\title{
The effect of bisphenol A on growth, pigment composition and photosystem II activity of Arabidopsis thaliana*
}

\author{
Michał Rąpała, Bartosz Pluciński and Paweł Jedynak ${ }^{\bowtie}$ \\ Department of Plant Physiology and Biochemistry, Faculty of Biochemistry, Biophysics and Biotechnology, Jagiellonian University in Cracow, \\ Kraków, Poland
}

Bisphenol A (BPA) is a widely used chemical, that can potentially be toxic to plants. In this study we examined the toxicity of 5-50 mg/l of BPA on Arabidopsis thaliana. Additionally, the effects of $0.5-5 \mathrm{mg} / \mathrm{l}$ of BPA were examined after four weeks of development. BPA had no effect on the germination rate and the chlorophyll $a / b$ ratio. The chlorophyll $a$ and carotenoid content was significantly elevated in seedlings treated with $5 \mathrm{mg} / \mathrm{l}$ of BPA. In 4-week-old plants there was no change in the chlorophyll and carotenoid content and photosynthetic parameters $\left(\mathrm{F}_{\mathrm{v}} / \mathrm{F}_{\mathrm{m}}, \mathrm{F}_{\mathrm{v}} / \mathrm{F}_{0}\right.$ and $\left.\mathrm{PI}\right)$ were unaffected, which suggests no photoinhibition. No oxidative stress symptoms were observed. BPA significantly decreased leaf protein content. A low concentration of BPA seems to have no significant effect on $A$. thaliana flowering, but further investigation is needed. The results obtained indicate that a low concentration of BPA has no negative effect on the growth and development of $A$. thaliana.

Key words: BPA, bisphenol A, Arabidopsis thaliana, seedlings, plants, chlorophyll

Received: 17 March, 2017; revised: 12 June, 2017; accepted: 12 June, 2017; available on-line: 27 July, 2017

\e-mail: p.a.jedynak@gmail.com

*The results were presented during the XLIV Winter School of the Faculty of Biochemistry, Biophysics and Biotechnology of the Jagiellonian University in Cracow (14-18 February 2017, Zakopane)

Abbreviations: BPA, bisphenol A; 2,2-bis(4-hydroxyphenyl)propane; $\mathrm{Chl}$, chlorophyll; $\mathrm{F}_{0}$, initial chlorophyll fluorescence intensity measured in PSIl; $F$ maximal chlorophyll fluorescence intensity; $F$ variable chlorophyll fluorescence $\left(F_{m}-F_{0}\right) ; F_{v} / F_{m}$ maximal quantum efficiency of photosystem II; $F_{v} / F_{0}$, oxygen-evolving complex efficiency; MDA, malondialdehyde; PI, performance index; PS II, photosystem II

\section{INTRODUCTION}

Bisphenol A (2,2-bis(4-hydroxyphenyl)propane or $\mathrm{BPA}$ ) is a chemical additive (Fig. 1) widely used in the production of carboxyplastics. It can be found in plastic bottles, notebooks and some paints (Goodson et al., 2002; Burridge 2003). As plastic ages some monomers of $\mathrm{BPA}$ can leak to the environment. This contamination is believed to be potentially harmful for living organisms. BPA mimic estrogenic activity, acting as an endocrine disruptor and can cause fertility problems (Mandich et al., 2007; Molina et al., 2013). Early-life BPA exposure

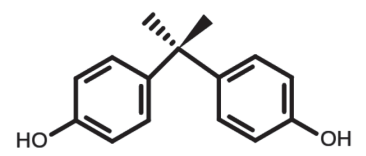

Figure 1. Chemical structure for BPA (drawn using ChemSpider). may increase the risk of breast cancer in animal model (Seachrist et al., 2016). BPA may affect human reproductive system and might promote prostate cancer (Tarapore et al., 2014). BPA is also linked with obesity and diabetes (Somm et al., 2009; Ranciere et al., 2015).

Fortunately, BPA is easily biodegradable by microalgae (Gattullo et al., 2012) and microorganisms present in water and soil (Matsumura et al., 2015; Ren et al., 2016). On the other hand, the prevalence of plastic pollution is a serious risk of continuous low-dose BPA exposure.

Scientific data regarding the toxic effect of BPA on plants is still scarce. It is known that some plants rapidly metabolize and absorb BPA in the form of glucoside conjugates (Nakajima et al., 2002). It was shown that a high concentration of BPA (above $10 \mathrm{mg} / \mathrm{l}$ ) has a negative effect on the growth and development of many plant species, including some important crops e.g. soybean (Qiu et al., 2013). In contrast, according to our knowledge low-dose effects of BPA on pigment composition in Arabidopsis thaliana have not been the subject of detailed studies. The impact of BPA on plants may be as complex as in animals, since mammal sex hormones are also produced by plants (Janeczko et al., 2005) and estrogen receptors have been found in plants (Janeczko et al., 2008). Thus, BPA can affect plants in both ways - as a toxic agent or by affecting particular estrogene-related regulatory pathways.

We were particularly interested in the low-dose and long-term effects of BPA on development of $A$. thaliana. $\mathrm{BPA}$ is a ubiquitous pollutant. However, in most cases its concentration in the environment is relatively low. Nevertheless, this does not mean such a concentration is safe for plants. Relatively few studies were done using plants older than one week. We checked the effect of a wide range of BPA concentrations on seedling pigment composition. The upper concentration of BPA was chosen arbitrarily, according to the concentrations described in other articles. We found a low concentration of BPA, which was particularly interesting, because we observed some simulative effects on pigment composition and no obvious stress symptoms. Then we checked the longterm (after four weeks) effects of BPA on the growth of A. thaliana, including changes in photosystem II (PSII) activity, stress symptoms as well as pigment composition.

\section{MATERIALS AND METHODS}

Plant material. Columbia ecotype (Col-0) of $A$. thaliana was used in all experiments. The seeds were obtained from Arabidopsis Biological Center (Ohio State University, Columbus, OH, USA). All of the seeds used in the experiments were collected from plants grown 
under standardized conditions, 12L:12D photoperiod at light intensity of $70-100 \mu \mathrm{mol} \times \mathrm{m}^{-2} \times \mathrm{s}^{-1}$ (Sylvania, Luxline plus), $80 \%$ humidity, and at $22 \pm 2^{\circ} \mathrm{C}$.

Medium preparation and growth conditions. The seeds were sterilized for 7 mins with 3\% hyperchlorite with an addition of $0.1 \%$ of Triton X-100 (Serva, Germany), washed thoroughly with sterile, deionized water and sown on glass Petri dishes or glass jars containing a Murashige and Skoog medium (Duchefa) with 1\% agar and 3\% sucrose (Sigma-Aldrich), as described in Malec et al. (2002). The growth medium was supplemented with sterile (filtered through a Whatman $0.2 \mu \mathrm{m}$ nylon filter) bisphenol A (Sigma-Aldrich) dissolved in 96\% ethanol (to a final concentration of $0.5 ; 1 ; 5 ; 25$ and $50 \mathrm{mg} / \mathrm{l}$ ). For the control experiments, ethanol was added to the medium $(0 \mathrm{mg} / 1$ of BPA) in order to eliminate inequality caused by the solvent. The ethanol concentration in the medium did not exceed $0.05 \%(\mathrm{v} / \mathrm{v})$ of the final growth medium volume. To avoid additional, unintentional BPA contamination all experiments were conducted using nitrile gloves and labolatory glasswere. The plants were placed at $4^{\circ} \mathrm{C} / 48 \mathrm{~h}$ for stratification, then grown in white light (Sylvania, Luxline plus; fluence rate 80-90 $\left.\mu \mathrm{mol} \times \mathrm{m}^{-2} \times \mathrm{s}^{-1}\right)$ at $22 \pm 2^{\circ} \mathrm{C}$ and $16 \mathrm{~L} / 8 \mathrm{D}$ photoperiod for 1 week or 4 weeks.

Calculating the germination rate. The seedlings with visible cotyledons were manually counted and divided by the number of sown seeds.

Chlorophyll $a$ fluorescence and photosystem II activity determination. Handy PEA fluorimeter (Hansatech Instruments) was used for estimating the photosynthetic parameters (including $\mathrm{F}_{\mathrm{v}} / \mathrm{F}_{\mathrm{m}}, \mathrm{F}_{\mathrm{v}} / \mathrm{F}_{0}, \mathrm{PI}$ ) in four-week old leaves. Before measuring, the plants were dark-adapted for 15 minutes.

Pigment composition. The chlorophyll and carotenoid content were estimated in $80 \%$ (v/v) acetone extracts according to Lichtentaler (1987). The antocyanin content was measured spectrophotometrically accroding to Muravyeva and coworkers (1984). 70-100 mg of plant material (seedlings or leaves) was used for each extraction.

Antioxidative potential. Extracts of powdered leaves from the four-week-old plants were obtained using methanol solution. EPR-based radical scavenging of
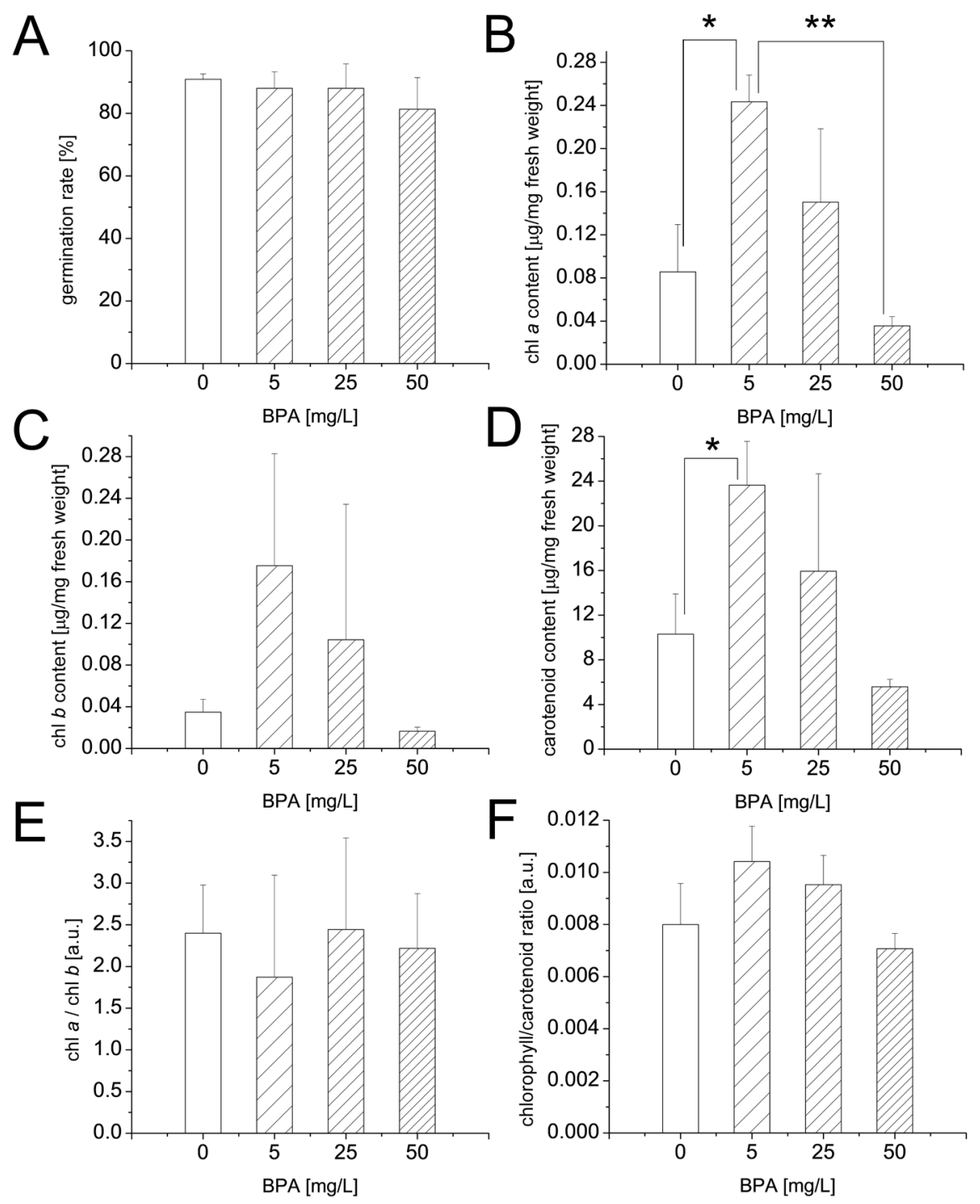

Figure 2. Effect of BPA-treatment on germination rate and pigment composition in one-week-old $A$. thaliana seedlings.

(A) in vitro germination rate of $A$. thaliana ecotype Columbia after one week in presence of $0,5,25$ or $50 \mathrm{mg} / \mathrm{l}$ of BPA. (B) Chl a, (C) chl $b$, (D) carotenoid content, (E) chl $a / b$ ratio and (F) chl/car ratio in seedling extracts. Germination rate was estimated using at least 100 seeds. All experiments were repeated four times. Significance was indicated with stars ${ }^{*} p<0.05 ;{ }^{* *} p<0.01$. Error bars - standard deviation. 
the extracts was carried out using $0.3 \mathrm{mM} \alpha$-diphenyl$\beta$-picrylhydrazyl (DPPH; Sigma-Aldrich). The spectra were measured at room temperature, using a MiniScope MS300 (Magnettech $\mathrm{GmbH}$ ) spectrometer with a frequency of $9.4 \mathrm{GHz}$, amplitude modulation of 2000 $\mathrm{mG}$, microwave power of $10 \mathrm{~mW}$ and scan rate $42 \mathrm{~g} /$ min (noise was reduced by averaging 6 scans for each sample).

Thiobarbituric acid reactive substances (TBARS) assay. The MDA content was measured spectrophotometrically using ethanol-based extracts of four-week-old leaves, according to the method described by Hodges and coworkers (1999).

Protein content. $50 \mathrm{mM}$ phosphate buffer ( $\mathrm{pH}$ 7.5) was used to extract soluble protein. The estimates were made spectrophotometrically using Bradford reagent (Sigma-Aldrich) and bovine serum albumine (Sigma-Aldrich) for a standard curve (Bradford, 1976). The samples were incubated per 15 minutes at $20 \pm 2^{\circ} \mathrm{C}$. All measurements were taken within the next 10 minutes.

Statistical analysis and normalization. The pigment content, antioxidative potential, protein and MDA con- tent were normalized to fresh weight. The statistical significance was estimated by analyzing the variance (oneway ANOVA), followed by two-tailed Tukey's post-hoc test. $P$-values less than 0.05 were considered to be significant. All analyses were carried out in $\mathrm{R}$ version 3.2.4 (codename "Very Secure Dishes") on Ubuntu. Graphs and correlation coefficient were produced using Origin 6.0 (OriginLab, Northampton, MA).

\section{RESULTS AND DISCUSSION}

\section{The effect of BPA on the early stages of $A$. thaliana development}

After one week of exposure BPA had no significant effect on the germination rate (Fig. 2A). This is consistent with previous observations regarding $A$. thaliana (Pan et al., 2013) and other species (Ferrara et al., 2006; Dogan et al., 2010; Dogan et al., 2012).

BPA had an adverse effect on chlorophyll $a$ and the total carotenoid content. $5 \mathrm{mg} / 1$ of BPA significantly

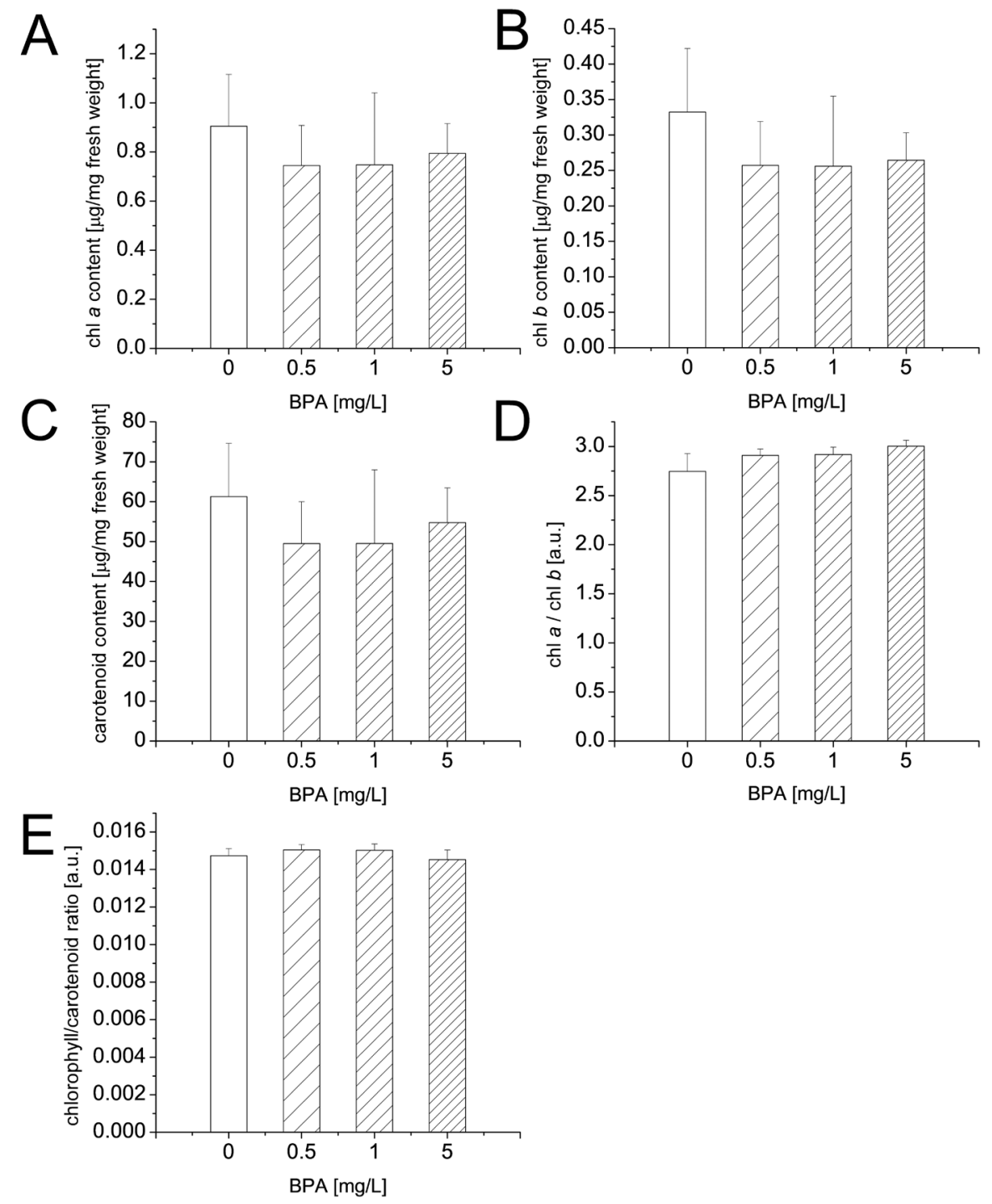

Figure 3. Effect of BPA-treatment on pigment composition in 4-week-old A. thaliana.

(A) Chl $a,(B) C h l b,(C)$ carotenoid content (D) chlorophyll a/b ratio, (E) chl/car ratio in extracts from leaves of 4-week-old plants. All experiments were repeated four times. Error bars - standard deviation. 
A
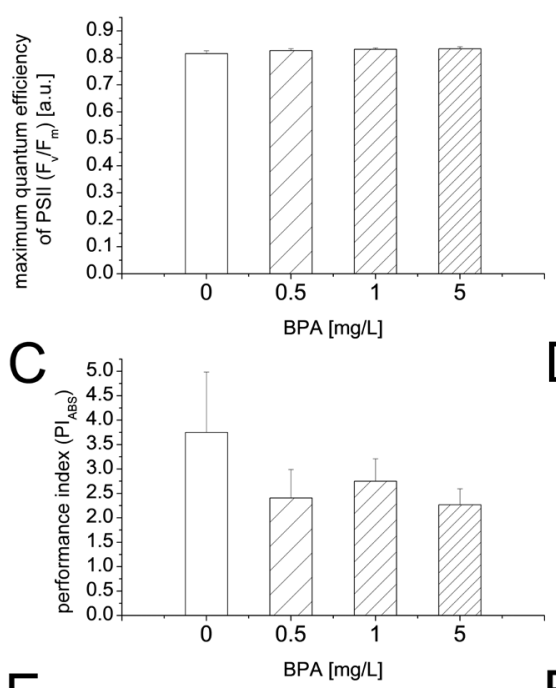

$\mathrm{E}$
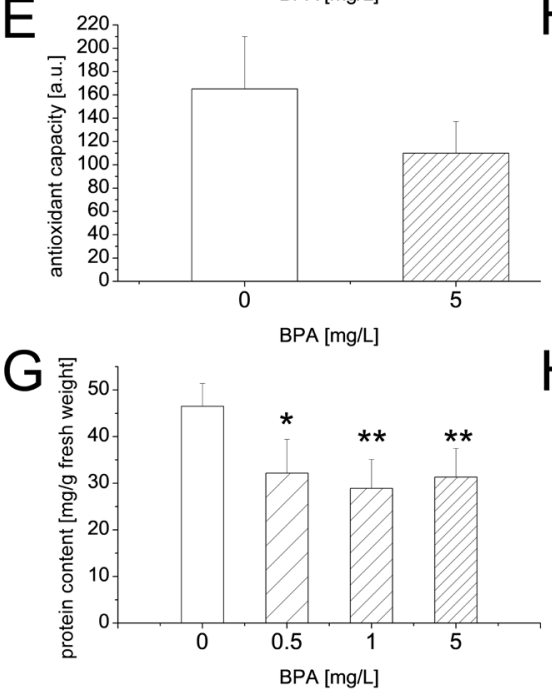

B
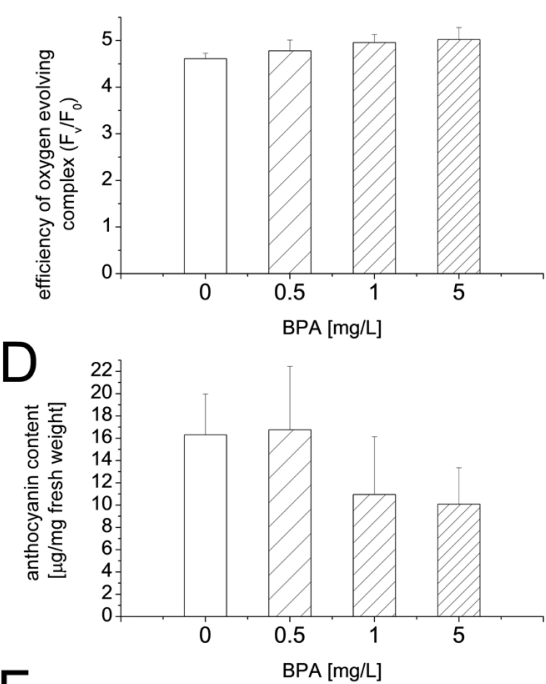

$\mathrm{F}$

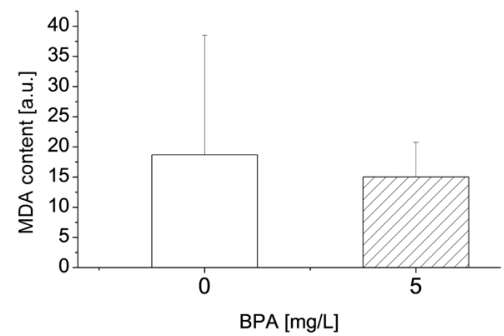

$\mathrm{H}$

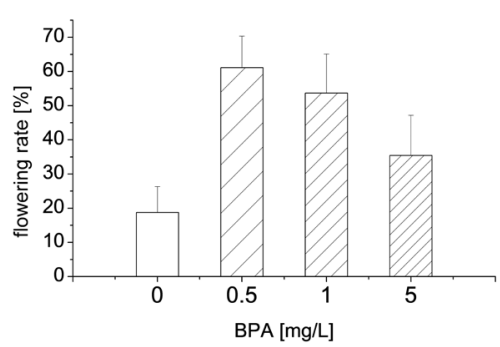

Figure 4. Physiological and biochemical characteristics of BPA-treated 4-week-old A. thaliana

Photosynthetic parameters (A) $F_{v} / F_{m^{\prime}}$ (B) $F_{v} / F_{0}$ and (C) PI estimated for 4-week-old BPA-treated plants. (D) Anthocyanin content, (E) DPPHbased EPR study of antioxidant potential, (F) MDA content in extracts from $A$. thaliana treated with 0 and $5 \mathrm{mg} / \mathrm{l}$ of BPA. (G) Protein content in plants treated with $0,0.5,1$ and $5 \mathrm{mg} / \mathrm{l}$ of BPA. Significance in comparison to control plants is indicated with stars ${ }^{*} p<0,05$; ${ }^{* *} p<0,01$. All experiments were repeated four times. Error bars - standard deviation. (H) Percentage of flowering 4-week-old A. thaliana plants. Error bars - standard error.

doubled chlorophyll $a$ and carotenoid content in seedlings treated (Fig. 2B and 2D). Higher concentrations of BPA (25 and $50 \mathrm{mg} / \mathrm{l}$ ) decreased the mean chlorophyll and carotenoid content in comparison to plants treated with $5 \mathrm{mg} / 1$ of $\mathrm{BPA}$, but the differences were statistically insignificant in comparison to control plants. However, the difference in chlorophyll a content between plants treated with 5 and $50 \mathrm{mg} / 1$ of BPA was statistically significant. Moreover, these changes in the chlorophyll $a, b$ and carotenoid content were dose dependent and inversely proportional to the BPA concentration. However, it must be emphasized, that chlorophyll $b$ content in plants treated with $25 \mathrm{mg} / 1$ of BPA varied greatly with no obvious outliers. Thus, these observations may be subject to considerable uncertainty. Nevertheless, BPA seems to have an adverse effect on chlorophyll accumulation. Treatment with $5 \mathrm{mg} / \mathrm{l}$ of BPA apparently stimulates chlorophyll accumulation but a higher BPA concentration decreases chlorophyll accumulation. The stimulatory effect of BPA on chlorophyll accumulation in A. thaliana has not been previously observed. However, a low BPA concentration (corresponding to approximately 0.2 and $1 \mathrm{mg} / \mathrm{l}$ ) has been shown to increase the fresh weight and promoted root development of $A$. thaliana seedlings, while higher BPA concentrations had the opposite effect (Pan et al., 2013). The stimulatory effect of low BPA-concentration on chlorophyll accumulation has been observed in other plants, especially in soybean seedlings ( $\mathrm{Hu}$ et al., 2014). BPA (1.5 $\mathrm{mg} / \mathrm{l})$ increases the activity of five enzymes, involved in chlorophyll biosynthesis (Jiao et al., 2015; Jiao et al., 2017). The positive effect of BPA on chlorophyll accumulation is probably not a result of its estrogenic activities, as low-dose heavy metal concentrations also increase chlorophyll content in plants (Maleva et al., 2009; Kumar et al., 2015). In our study the stimulatory effect of BPA on chlorophyll accumulation was observed at $5 \mathrm{mg} / 1$ of BPA. No change in the chlorophyll to carotenoid ratio (considered as a stress indicator in $A$. thaliana which correlates with photoinhibition) suggesting, that the physiology of $A$. thali- 
ana seedlings was not negatively altered by BPA in these conditions (Fig. 2F). This may indicate a high level of tolerance to BPA pollution (thus, its relatively low toxicity) in the early stages of $A$. thaliana growth. BPA had no significant effect on the chlorophyll $a / b$ ratio (Fig. 2E) and apparently does not affect the PS I and PS II antenna stoichiometry in seedlings.

\section{The effects of BPA-treatment on A. thaliana after 4 weeks of development}

Measuring chlorophyll $a$ fluorescence in vivo is an important tool for estimating photosynthesis-related parameters. In dark adapted leaves a millisecond flash of light induces rapid fluctuations in chlorophyll fluorescence, which is correlated with photochemical reactions during photosynthesis. As a result, the characteristic OJIP curve of light emission can be recorded, as reviewed in Misra and coworkers (2012). The initial chlorophyll fluorescence yield, $\mathrm{F}_{0}$, can be recorded after $20 \mu \mathrm{s}$ upon excitation with photosynthetically inactive light and represents conditions with fully oxidized plastoquinone pool. The second pulse of photosynthetically active light induces intense fluorescence, described as $\mathrm{F}_{\mathrm{m}}$ and which represents the maximal fluorescence yield in the absence of photochemical quenching. $F_{m}$ is reached when the primary electron acceptor pool in PS II is fully reduced and energy transfer from the excited chlorophyll is impossible. A comparison of these values, expressed as $\left(\mathrm{F}_{\mathrm{m}}-\right.$ $\left.\mathrm{F}_{0}\right) / \mathrm{F}_{\mathrm{m}}$ or $\mathrm{F}_{\mathrm{v}} / \mathrm{F}_{\mathrm{m}}$ ratio allows us to estimate the maximal quantum efficiency of PS II. Other parameters can be described using a OJIP curve, including oxygen-evolving complex efficiency $\left(\mathrm{F}_{\mathrm{v}} / \mathrm{F}_{0}\right)$ and performance index (PI) (Maxwell et al., 2000; Misra et al., 2012; Kalaji et al., 2014).

In our study BPA did not affect PSII activity in A. thaliana, as $\mathrm{F}_{\mathrm{v}} / \mathrm{F}_{\mathrm{m}}, \mathrm{F}_{\mathrm{v}} / \mathrm{F}_{0}$ and $\mathrm{PI}$ were not significantly altered (Fig. 4A, 4B and 4C). Therefore, BPA caused no photoinhibition. It was observed, that low doses of BPA may even stimulate photosynthesis and increase $F_{v} / F_{m}$ in seedlings of particular crops, but the effect was dependent on BPA concentration and the species susceptibility (Zhang et al., 2015).

BPA treatment had no effect on plant size and BPA had no significant effect on the chlorophyll (Fig. 3A and 3B) and carotenoid (Fig. 3C) content in A. thaliana. Our observations suggest that BPA had no effect on PS I and PS II antenna stoichiometry in 4-week-old plants, as no change in the chlorophyll $a / b$ ratio was observed.

BPA had no significant effect on the anthocyanin content (Fig. 4D) and chlorophyll/carotenoid ratio (Fig. 3E). No significant change in antioxidative potential was observed either (Fig. 4E). Additionally, MDA content was also similar in BPA-treated and control plants (Fig. 4F), but these results may be subject to considerable uncertainty. Nevertheless, no significant oxidative stress symptoms were observed, indicating that low-dose (up to $5 \mathrm{mg} / \mathrm{l})$ BPA pollution may be relatively safe for plants. Our results contradict some other findings, where BPA exposure had a severe effect on $A$. thaliana development (Tian et al., 2014). Accroding to this research, the minimal, considerably toxic, BPA concentration for $A$. thaliana exceeds $10 \mathrm{mg} / 1(50 \mu \mathrm{M})$. Such a BPA concentration is observed in heavily polluted and environmentally devastated, industrial areas (Yamamoto et al., 2001). However, much lower concentration of BPA in soil and water is more probable in agricultural fields. In German rivers the BPA concentration was estimated to be about 0.41 $\mathrm{mg} / \mathrm{l}$ (Fromme et al., 2002). Our data suggest that low- dose BPA exposure may not be directly dangerous to plants that grow in non-industrial areas and in agricultural fields, polluted only by typical plastic waste.

Although we found no statistically significant differences in antioxidant potential and anthocyanin content, it is worth emphasizing that BPA-treated plants had a lower mean content of antioxidants. Thus, low-dose BPA-treatment seems to decrease antioxidant capacity in some plants. It seems possible that even a low concentration of BPA had some negative effect on particular individuals in the population. It may be possible that some of defence mechanisms were weakened by BPA, making these plants more susceptible to other environmental stresses. In optimal laboratory conditions, differences might be meaningless, but in wild, polluted population can make a difference. Furthermore, in an agricultural field even low-dose BPA pollution may decrease plant yields. This is an important issue, especially considering the gradual decrease of protein content in BPA-treated plants. Protein content was significantly lowered in BPA-treated plants (Fig. 4G) and these results were dose-dependent. Leaf protein content seems to correlate with yield quality and protein content in the seeds of legumes (Nielsen et al., 1994). Apparently, no information about the effect of BPA on the nutritional value of legume seeds is available. Importantly, nitrogen deficiency may decrease the soluble protein content in particular plants e.g. sunflowers (Pankovic et al., 2000). However, such an effect was not observed in A. thaliana but the yield (number of seeds) was reduced in those conditions (Lemaitre et al., 2008). $1.5 \mathrm{mg} / \mathrm{l}$ of BPA stimulates nitrogen accumulation in soybean (Glycine $\max$ ) roots and the seedlings displayed higher fresh and dry weight (Sun et al., 2013). Higher concentrations of BPA had the opposite effect. Interestingly, a low concentration of exogenous estrogens had a similar effect on the roots of $A$. thaliana, increasing the protein content and dry mass (Kopcewicz et al., 1970a). BPA may have a similar, regulatory effect on the early stages of the growth of $A$. thaliana. Therefore, it is possible, that intense nitrogen assimilation at an early stage of growth may reduce its content in the medium, leading to its being insufficiently supplemented during later stages. As protein content was measured in leaves only, it is possible, that BPA treatment may change nitrogen allocation between the shoot and root. The nitrogen shoot:root ratio allocation depends on nitrogen abundance, as shown in many crops (Lemaitre et al., 2008). On the other hand BPA may affect $\mathrm{N}$ partitioning between protein and pigment biosynthesis (as chlorophyll content was increased in seedlings). Therefore, the allocation of nitrogen in the chlorophyll pool reduces its availability, as chlorophyll and products of its degradation generally not release this macronutrient. Thus, the nitrogen pool for protein recirculation might be reduced in BPA-treated plants, especially at a later stage of development. Most of the cellular proteins are involved in photosynthesis, of which RuBisCO makes up up to $50 \%$ of soluble proteins (Spreitzer and Salvucci, 2002). Therefore, the reduced soluble protein content may be considered to be a reduced RuRisCO content (Mate et al., 1993) and perhaps activity too. However, even a $50 \%$ reduction in the normal RuBisCO content had no visible effect on the photosynthesis rate and $\mathrm{CO}_{2}$ assimilation (Quick et al., 1991). As carbon and nitrogen metabolism are co-regulated (Ferrario-Méry et al., 1998), the change in protein content may reflect altered carbohydrate accumulation as well as the content of soluble nitrogen-containing compounds (and water content) (Neto et al., 2009). 
The decreased protein content (associated with nitrogen deficiency) has little impact on the $F_{v} / F_{m}$ ratio in maize and the first negative effects occurred in 5-weekold plants (Ding et al., 2005). Thus, the decreased protein content in $A$. thaliana may have no visible trace in plant development and its negative effects may be delayed.

The leaf protein content correlates negatively with the chlorophyll $a / b$ ratio in some plants, especially in high light conditions (Kitajima et al., 2003). Although in our experimental model the mean values of the chlorophyll $a / b$ ratio were slightly increased in BPA-treated plants, the difference was insignificant (Fig. 3D) and had no correlation to BPA concentration.

Apparently, the decreased soluble protein content did not indicate stress in BPA-treated plants, because the protein content in plants exposed to different types of stress conditions usually increases or no significant change was observed (Gonçalves et al., 2007; Neto et al., 2009; Azymi et al., 2012).

A concentration of $0.5 \mathrm{mg} / 1$ of BPA increased the number of flowering plants (Fig. $4 \mathrm{H}$ ) and a BPA concentration higher than $0.5 \mathrm{mg} / \mathrm{l}$ might have a less stimulatory effect as the mean number of flowering plants decreased in a dose-dependent manner in comparison to those plants treated with $0.5 \mathrm{mg} / \mathrm{l}$. However, these results were not statistically significant. Still, the mean values of the flowering rate were higher in BPA-treated plants. Therefore, we cautiously assume that BPA may have a positive effect on flowering, but further investigation is essential to gather more evidence for that thesis. According to our knowledge such effect was not previously observed. On the contrary, some evidence suggests the opposite effect as a very low BPA concentration (as low as $10 \mathrm{nM}$ - less than $0.01 \mathrm{mg} / \mathrm{l}$ ) inhibits flowering in $A$. thaliana (Tian et al., 2014). Stress conditions often accelerate flowering in plants. However, in the case of our study no obvious stress symptoms occurred. Hence, it seems that BPA might indeed induce generative phase in $A$. thaliana. Importantly, exogenous estrogens were shown to induce flowering in particular plant species (Kopcewicz, 1970b). It is an open question, whether BPA, an estrogene-mimicing substance, could possibly act in a similar way. Some evidence suggests that BPA may increase the endogenous production of steroid hormones (17 $\beta$-estradiol and testosterone, in particular) in kiwifruit ( $A c$ tinidia deliciosa) pollen and thus inhibit its germination (Speranza et al., 2011). Estrogens also have a negatively affect on auxin content (Kopcewicz, 1970a). Notably, auxins and ethylene are hormones involved in the control of flowering and it was suggested, that BPA may interfere negatively with auxin regulation, as well as decrease the expression of particular ethylene- and auxin-dependent genes (Tian et al., 2014; Frejd et al., 2016).

BPA is and probably still will be one of the most ubiquitous environmental pollutants. Even with limitations, there is a risk of the influential effect of BPA on the environment. Our findings indicate that BPA induces unexpected changes in plant physiology and biochemistry. Thus, further research on the role of a low BPA concentration on plant physiology is essential.

\section{CONCLUSIONS}

A low concentration of BPA (up to $5 \mathrm{mg} / \mathrm{l}$ ) does not induce oxidative stress symptoms and photoinhibition in A. thatiana.

BPA at a concentration of $5 \mathrm{mg} / \mathrm{l}$ has a stimulatory effect on chlorophyll and carotenoid accumulation in one-week-old seedlings of $A$. thatiana.
BPA does not affect PSII activity and overall photosynthesis efficiency in 4-week-old plants.

A low concentration of BPA (up to $5 \mathrm{mg} / \mathrm{l}$ ) decrease protein content in 4 -week-old plants.

\section{Conflicts of interest}

The authors declare that there is no conflict of interest regarding the publication of this article.

\section{Acknowledgements}

The authors would like thank Beata Mysliwa-Kurdziel $(\mathrm{PhD})$ and Monika Rak (PhD) for their participation in the project and support. We are also grateful to Przemyslaw Malec (PhD) for his continuous encouragement, support and valuable advice. We thank an anonymous reviewer for constructive comments.

This work was supported by grant MNiSW/2015/ DIR/14/UMW from the Ministry of Science and Higher Education (MNiSW). The research was conducted within the framework of the University of Young Inventors programme. It was co-financed by the European Regional Development Fund within the Operational Programme Innovative Economy.

\section{REFERENCES}

Azymi S, Sofalian O, Jahanbakhsh G, Khomari S (2012) Effect of chilling stress on Soluble Protein, sugar and Prolin accumulation in cotton (Gossypium hirsutum L.) genotypes. Intl J Agri Crop Sci 4: 825-830

Bradford MM (1976) A rapid and sensitive method for the quantitation of microgram quantities of protein utilizing the principle of protein-dye binding. Anal Biochem 72: 248-254. http://dx.doi. org/10.1016/0003-2697(76)90527-3

Burridge E (2003) Bisphenol A: product profile. European Chemical News 17: $14-20$

ChemSpider, http://www.chemspider.com/Chemical-Structure.1906. html, accessed 13.04.2017

Ding L, Wang KJ, Jiang GM, Biswas DK, Xu H, Li LF, Li YH (2005) Effects of nitrogen deficiency on photosynthetic traits of maize hybrids released in different years. Annals Bot 96: 925-930. http://doi. org $/ 10.1093 / \mathrm{aob} / \mathrm{mci} 244$

Dogan M, Yumrutas O, Saygideger S, Korkunc M, Gulnaz O, Sokmen A (2010) Effects of bisphenol A and tetrabromobisphenol A on chickpea roots in germination stage. Am-Eurasian J Agric Environ Sci 9: 186-192

Dogan M, Korkunc M, Yumrutas O (2012) Effects of bisphenol A and tetrabromobisphenol A on bread and durum wheat varieties. Ekoloji 21: 114-122. 10.5053/ekoloji.2012.8513

Ferrara G, Loffredo E, Senesi N (2006) Phytotoxic, clastogenic and bioaccumulation effects of the environmental endocrine disruptor bisphenol A in various crops grown hydroponically. Planta 223: 910-916. 910. 10.1007/s00425-005-0147-2

Ferrario-Méry S, Valadier M-H, Foyer CH (1998) Overexpression of nitrate reductase in tobacco delays drought-induced decreases in nitrate reductase activity and mRNA. Plant Physiology 117: 293-302.

Frejd D, Dunaway K, Hill J, van Maanen J, Carlson C (2016) The genomic and morphological effects of bisphenol A on Arabidopsis thaliana. PLoS One 11: e0163028. 10.1371/journal.pone.0163028

Fromme H, Küchler T, Otto T, Pilz K, Müller J, Wenzel A (2002) Occurrence of phthalates and bisphenol $\mathrm{A}$ and $\mathrm{F}$ in the environment. Water Res 36: 1429-1438. http://dx.doi.org/10.1016/S00431354(01)00367-0

Gattullo CE, Bährs H, Steinberg CE, Loffredo E (2012) Removal of bisphenol A by the freshwater green alga Monoraphidium braunii and the role of natural organic matter. Sci Total Environ 416: 501-506. 10.1016/j.scitotenv.2011.11.033

Gonçalves JF, Becker AG, Cargnelutti D, Tabaldi LA, Pereira LB, Battisti V, Spanevello RM, Morsch VM, Nicoloso FT, Schetinger MRC (2007) Cadmium toxicity causes oxidative stress and induces response of the antioxidant system in cucumber seedlings. Brazilian Journal of Plant Physiology 19: 223-232. https://dx.doi.org/10.1590/ S1677-04202007000300006

Goodson A, Summerfield W, Cooper I (2002) Survey of bisphenol A and bisphenol F in canned foods. Food Addi Contam 19: 796-802. $10.1080 / 02652030210146837$

Hodges, D, DeLong, J, Forney, C, Prange R (1999) Improving the thiobarbituric acid-reactive-substances assay for estimating lipid per- 
oxidation in plant tissues containing anthocyanin and other interfering compounds. Planta 207: 604-611. 10.1007/s004250050524

Hu H, Wang L, Wang Q, Jiao L, Hua W, Zhou Q, Huang X (2014) Photosynthesis, chlorophyll fluorescence characteristics, and chlorophyll content of soybean seedlings under combined stress of bisphenol A and cadmium. Environ Toxicol Chem 33: 2455-2462. 10.1002/etc. 2720 .

Janeczko A, Budziszewska B, Skoczowski A, Dybała M (2008) Specific binding sites for progesterone and 17 $\beta$-estradiol in cells of Triticum aestivum L. Acta Biocbim Polon 55: 707-711. 10.1.1.337.2839

Janeczko A, Skoczowski A (2005) Mammalian sex hormones in plants. Folia Histochem Cytobiol 43: 71-79

Jiao L, Ding H, Wang L, Zhou Q, Huang X. (2017) Bisphenol A effects on the chlorophyll contents in soybean at different growth stages. Environmental Pollution 223: 426-434 http://dx.doi. org/10.1016/j.envpol.2017.01.042

Jiao L, Wang L, Qiu Z, Wang Q, Zhou Q, Huang X (2015) Effects of bisphenol A on chlorophyll synthesis in soybean seedlings. Environ Sci Pollut Res Int 22: 5877-5886. 10.1007/s11356-014-3764-0

Kalaji HM, Schansker G, Ladle RJ, Goltsev V, Bosa K, Allakhverdiev SI, Brestic M, Bussotti F, Calatayud, Dąbrowski P, Elsheery NI, Ferroni L, Guidi L, Hogewoning SW, Jajoo A, Misra AN, Nebauer SG, Pancaldi S, Penella C, Poli D, Pollastrini M, Romanowska-Duda ZB, Rutkowska B, Serôdio J, Suresh K, Szulc W, Tambussi E, Yanniccari M, Zivcak M (2014) Frequently asked questions about in vivo chlorophyll fluorescence: practical issues. Photosynth Res Nov 122: 121-158. 10.1007/s11120-014-0024-6

Kitajima K, Hogan KP (2003) Increases of chlorophyll a/b ratios during acclimation of tropical woody seedlings to nitrogen limitation and high light. Plant Cell Environ 26: 857-865

Kopcewicz J (1970a) Influence of estrogens on the flower formation in Cichorium intybus L. Naturwissenschaften 57: 136. http://dx.doi. org/10.1007/BF00600070

Kopcewicz J (1970b) Effect of estradiol-17beta, estrone and estriol on the endogenous auxins content in plants. Acta Soc Bot Pol 39: 339 346. 10.5586/asbp.1970.02610.5586/asbp.1970.026

Kumar A, Prasad MNV (2015) Lead-induced toxicity and interference in chlorophyll fluorescence in Talinum triangulare grown hydroponically. Photosynthetica 53: 66-71. 10.1007/s11099-015-0091-8

Lemaittre T, Gaufichon L, Boutet-Mercey S, Christ A, MasclauxDaubresse C (2008) Enzymatic and metabolic diagnostic of nitrogen deficiency in Arabidopsis thaliana Wassileskija accession. Plant Cell Physiol 49: 1056-1065. https://doi.org/10.1093/pcp/pcn081

Lichtenthaler HK, (1987) Chlorophylls and carotenoids: pigments of photosynthetic membranes. Methods Ensymol 148: 350-382. http:// dx.doi.org/10.1016/0076-6879(87)48036-1

Malec P, Yahalom A, Chamovitz DA (2002) Identification of a lightregulated protein kinase activity from seedlings of Arabidopsis thaliana. Photochem Photobiol 75: 178-183. 10.1562/0031-8655(2002)0750178IOALRP2.0.CO2

Maleva MG, Nekrasova GF, Malec P, Prasad MN, Strzałka K (2009) Ecophysiological tolerance of Elodea canadensis to nickel exposure. Chemosphere 77: 392-398. 10.1016/j.chemosphere.2009.07.024

Mandich A, Bottero S, Benfenati E, Cevasco A, Erratico C, Maggioni S, Massari A, Pedemonte F, Vigano L (2007) In vivo exposure of carp to graded concentrations of bisphenol A. Gen Comp Endocrinol 153: 15-24. http://dx.doi.org/10.1016/j.ygcen.2007.01.004

Mate CJ, Hudson GS, von Caemmerer S, Evans J R, Andrews TJ (1993). Reduction of ribulose biphosphate carboxylase activase levels in tobacco (Nicotiana tabacum) by antisense RNA reduces ribulose biphosphate carboxylase carbamylation and impairs photosynthesis. Plant Physiology 102: 1119-1128

Matsumura Y, Akahira-Moriya A, Sasaki-Mori M (2015) Bioremediation of bisphenol A polluted soil by Sphingomonas bisphenolicum AO1 and the microbial community existing in the soil. Biocontrol Sci 20: 35-42. 10.4265/bio. 20.35

Maxwell K, Johnson GN (2000) Chlorophyll fluorescence - a practical guide. J Exp Bot 51: 659-68

Misra AN, Misra M, Singh R (2012) Chlorophyll fluorescence in plant biology. In Biophysics (Misra AN ed), pp 171-192. Rijeka, Croatia: InTech. 10.5772/1877

Molina AM, Lora AJ, Blanco A, Monterde JG, Ayala N, Moyano R (2013) Endocrine-active compound evaluation: qualitative and quantitative histomorphological assessment of zebrafish gonads after bisphenol A exposure. Ecotoxicol Environ Saf 88: 155-162. 10.1016/j. ecoenv.2012.11.010
Muravyeva DA, Bubenchikova VN, Belikov V (1984) Spectrophotometric determination of the total anthocyanins amount in the flowers of cornflower blue. Pharmacy 36: 28-29

Nakajima N, Ohshima Y, Serizawa S, Kouda T, Edmonds JS, Shiraishi F, Aono M, Kubo A, Tamaoki M, Saji H (2002) Processing of bisphenol A by plant tissues: Glucosylation by cultured BY-2 cells and glucosylation/translocation by plants of Nicotiana tabacum. Plant Cell Physiol 43: 1036-1042. https://doi.org/10.1093/pcp/pcf130

Neto AD, Prisco JT, Gomes-Filho E (2009) Changes in soluble amino-N, soluble proteins and free amino acids in leaves and roots of salt-stressed maize genotypes. J Plant Inter 4: 137-144. $10.1080 / 17429140902866954$

Nielsen SS, Osuala CI, Brandt WE (1994) Early leaf harvest reduces yield but not protein concentration of cowpea seeds. Hort Science 29: 631-632

Pan WJ, Xiong C, Wua QP, Liu JX, Liao HM, Chen W, Liu YS, Zheng L (2013) Effect of BPA on the germination, root development, seedling growth and leaf differentiation under different light conditions in Arabidopsis thaliana. Chemosphere 93: 2585-2592

Pankovic D, Plesnic M, Arsenijevic-Maksimovic I, Petrovic N, Sakac Z, Kastori R (2000) Effects of nitrogen nutrition on photosynthesis in Cd-treated sunflower plant. Annals of Botany 86: 841-847. doi:10.1006/anbo.2000.1250

Spreitzer RJ, Salvucci ME (2002) Rubisco: structure, regulatory interactions, and possibilities for a better enzyme. Annu Rev Plant Biol 53: 449-475

Qiu Z, Wang L, Zhou Q (2013) Effects of bisphenol A on growth, photosynthesis and chlorophyll fluorescence in above-ground organs of soybean seedlings. Chemosphere 90: 1274-1280. 10.1016/j. chemosphere.2012.09.085

Quick WP, Schur U, Fichtner K, Schulze E-D, Roderme SR, Bogorad L, Stitti M (1991) The impact of decreased Rubisco on photosynthesis, growth, allocation and storage in tobacco plants which have been transformed with antisense rbcS. The Plant Journal 1: 51-58. 10.1111/j.1365-313X.1991.00051.x.

Ranciere F, Lyons JG, Loh VHY, Botton J, Galloway T, Wang T, Shaw JE, Magliano DJ (2015) Bisphenol A and the risk of cardiometabolic disorders: a systematic review with meta-analysis of the epidemiological evidence. Environ Health 14: 46. 10.1186/s12940015-0036-5

Ren L, Jia Y, Ruth N, Shi Y, Wang J, Qiao C, Yan Y (2016) Biotransformations of bisphenols mediated by a novel Arthrobacter sp. strain YC-RL. Appl Microbiol Biotechnol 100: 1967-1976. 10.1007/s00253015-7076-1

Seachrist DD, Bonk KW, Ho SM, Prins GS, Soto AM, Keri RA (2016) A review of the carcinogenic potential of bisphenol A. Reprod Toxicol 59: 167-182. 10.1016/j.reprotox.2015.09.006

Somm E, Schwitzgebel VM, Toulotte A, Cederroth CR, Combescure C, Nef S, Aubert ML, Hüppi PS (2009) Perinatal exposure to bisphenol a alters early adipogenesis in the rat. Environ Health Perspect 117: 1549-1555. 10.1289/ehp.11342

Speranza A, Crosti P, Malerba M, Stocchi O, Scoccianti V (2011) The environmental endocrine disruptor, bisphenol A, affects germination, elicits stress response and alters steroid hormone production in kiwifruit pollen. Plant Biol (Stuttg) 13: 209-217. 10.1111/j.14388677.2010.00330.x

Sun H, Wang LH, Zhou Q (2013) Effects of bisphenol A on growth and nitrogen nutrition of roots of soybean seedlings. Environ Toxicol Chem 32: 174-180.10.1002/etc.2042

Tarapore P, Ying J, Ouyang B, Burke B, Bracken B, Ho SM (2014) Exposure to bisphenol A correlates with early-onset prostate cancer and promotes centrosome amplification and anchorage-independent growth in vitro. PLoS One 9: e90332. 10.1371/journal.pone.0090332

Tian YS, Jin XF, Fu XY, Zhao W, Han HJ, Zhu B, Liu M, Yao QH (2014) Microarray analysis of differentially expressed gene responses to bisphenol A in Arabidopsis. J Toxicol Sci 39: 671-679

Yamamoto T, Yasuhara A, Shiraishi H, Nakasugi O (2001) Bisphenol $\mathrm{A}$ in hazardous waste landfill leachates. Chemosphere 42: 415-418. http://dx.doi.org/10.1016/S0045-6535(00)00079-5

Zhang J, Wang L, Li M, Jiao L, Zhou Q, Huang X (2015) Effects of bisphenol A on chlorophyll fluorescence in five plants. Environ Sci Pollut Res Int 22: 17724-17732. 10.1007/s11356-015-5003-8 